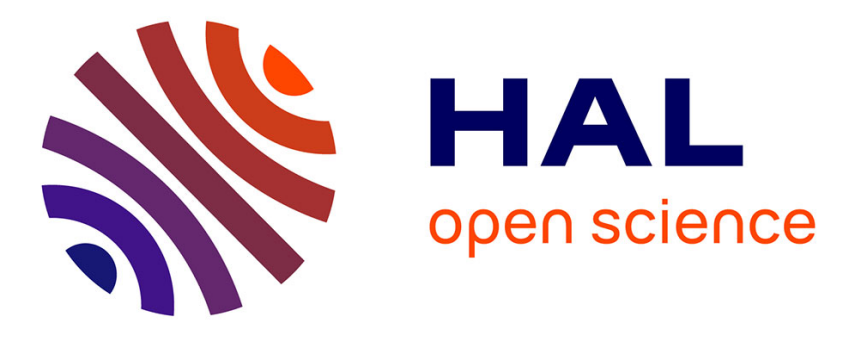

\title{
Robust hybrid control based on Petri Nets for a multicellular inverter
}

Sana Othman, Mohammed Alaa-Eddine Allali, Iman Mrad, Dhia Elhak Chariag, Malek Ghanes, Lassaad Sbita, Jean-Pierre Barbot

\section{To cite this version:}

Sana Othman, Mohammed Alaa-Eddine Allali, Iman Mrad, Dhia Elhak Chariag, Malek Ghanes, et al.. Robust hybrid control based on Petri Nets for a multicellular inverter. 2020 6th IEEE International Energy Conference (ENERGYCon), Sep 2020, Gammarth (virtual), Tunisia. pp.143-148, 10.1109/ENERGYCon48941.2020.9236506 . hal-03153428

\section{HAL Id: hal-03153428 \\ https://hal.science/hal-03153428}

Submitted on 7 Mar 2021

HAL is a multi-disciplinary open access archive for the deposit and dissemination of scientific research documents, whether they are published or not. The documents may come from teaching and research institutions in France or abroad, or from public or private research centers.
L'archive ouverte pluridisciplinaire HAL, est destinée au dépôt et à la diffusion de documents scientifiques de niveau recherche, publiés ou non, émanant des établissements d'enseignement et de recherche français ou étrangers, des laboratoires publics ou privés. 


\section{Robust hybrid control based on Petri Nets for a multicellular inverter}

\author{
$1^{\text {st }}$ Sana Othman \\ ENIG University of Gabes \\ ENSEA University of Cergy Pontoise
}

\author{
$3^{\text {rd }}$ Iman Mrad \\ ENIG University of Gabes \\ ENSEA University of Cergy Pontoise
}

\author{
$7^{\text {th }}$ Jean-Pierre Barbot \\ Professor of Universities
}

\author{
Professor of Universities \\ ENIG University of Gabes \\ $6^{\text {th }}$ Lassaad Sbita
}

\author{
$4^{\text {th }}$ Dhia Elhak Chariag \\ Professor of Universities \\ ENIG University of Gabes \\ $5^{\text {th }}$ Malek Ghanes \\ CNRS University of Nantes
}

\begin{abstract}
In this study, a robust control method of a serial multicellular inverter is suggested. This particular hybrid system represents a combination of three switching cells interconnected via two flying capacitors. These continuous and discrete variables confer a hybrid dynamical behavior which induces difficult control problems. To tackle these problems, a comparison between two different approaches has been done. First, we propose the conventional PWM control with triangular carriers. Then, a new control concept based on Petri Nets was developed and tested. This methodology shows the versatility of controlling the flying capacitor voltages and the output current. Provided simulation results certify the efficiency and the robustness of Petri Nets formalism to control this type of converters.

Index Terms-Multicellular converter, Flying capacitor converter, Hybrid dynamic system, PWM control, Petri Nets control
\end{abstract}

\section{INTRODUCTION}

Power electronics have undergone significant technological development [1]. Nowadays, we can synthesize high voltage multilevel waveforms [2] using low voltage power semiconductors. this discipline affects several fields of application from a few watts to several hundred of megawatts [3], such as the control of electrical machines [4], railway traction [5], the transport of electrical energy in high voltage direct current HVDC [6] and parallel active filtering [7], [8]... Thus, serial multicellular converter [9] has gained fundamental interest in high power systems. The topology of multicellular structures is relatively new, it was introduced at the beginning of the 1990's, it distributes the high voltages over a series of switching cells which are linked with floating voltage sources. This structure greatly improved the waveform harmonic content [8]. It can be adapted to all types of configurations including chopper or inverter, we have treat the case of an inverter with a capacitive medium point. In this way, with $\mathrm{p}=\mathrm{N}-1$ commutation cells we can obtain $\mathrm{N}$ voltage levels. For an equal distribution of the voltage in the switches, the floating voltage sources set the measurment of the voltages of each cell to a value equal to $\frac{E}{p}$. So, the voltages across the floating capacitors must be balanced within a certain interval around the desired value of $\frac{k * E}{p}$ with
$\mathrm{k}$ is the number of the corresponding cell. Accordingly, the most problematic factor is how to balance the flying capacitor voltages and how to assure a good tracking of the load current. For these reasons, a wide variety of approaches proved high dynamic performance of this structure.

However, the problem of capacitor voltage imbalance is caused by the high level of output voltage. This imbalance can be addressed by simple control strategies in open or closed loop. Open loop schemes rely on the natural balancing property. Studies [10], [11] show the natural balance with an open loop.

Moreover, an auxiliary resistive - capacitive - inductive resonant circuit connected in parallel with the load improves the natural balancing dynamics of the output voltage [12]. It can be noted that the auxiliary circuits increase the losses.

This is why we find that closed-loop control improves balancing. Indeed, in a closed loop, the variables are measured or estimated and compared to reference values. Then a control signal is produced based on the errors. Some researches are based on checking capacitor voltages only, and others regulate the voltages of the capacitors and the output current simultaneously.

In addition to the above diagrams, hysteresis controllers have also been proposed. for their popularity which lies in its excellent dynamic performance despite uncertainties or variations in parameters.

The aim of this paper is to propose two control strategies for multicellular converters. We introduced at first the conventional PWM control [13] which is chosen for its simplicity of implementation. Using this method, voltage balancing is naturally assured but with a slowdown in the dynamic properties. Then, we propose a closed loop control scheme based on Petri Nets to solve the problem of current and voltage regulation. Petri Nets have been widely used as a tool for analysis and modeling of hybrid systems. The fields of application of this strategy are: industrial processes, software development 
methodologies, modeling and analysis of electrical networks, special industrial supervision and modeling for warehouse systems.

This control strategy is based on hysteresis-type regulation in order to follow the reference current it is important for improving content of the output energy and the efficiency of the system by the reduction of the switching losses. The performance of these controls is demonstrated for a 3-cell inverter connected to an inductive load, and the main contribution of this strategy is the robust control of this type of inverter ensuring current regulation and voltage balancing.

This present paper is organized as follows: In section 2 we determine the multicellular inverter hybrid model. Section 3 presents PWM and Petri Nets controller design. In section 4, the proposed Petri Nets control is tested and the results are compared with PWM control and discussed.

\section{HybRid STATE MODEL OF MULTICELLULAR INVERTER}

A hybrid model [14] with instantaneaous values for a 3-cell inverter will be explained in this section. This model allows the study of the evolution of the different states in order to use it to test the proposed control methods. A multicellular midpoint series inverter is connected to an R-L load as shown in (Fig1):

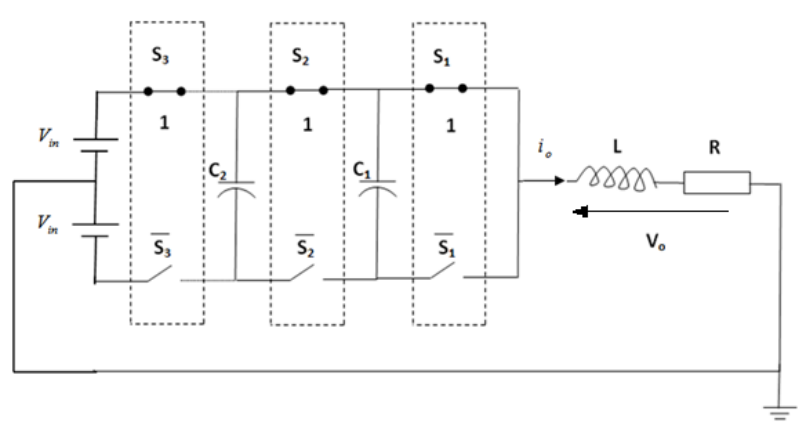

Fig. 1. Structure of 3-cell inverter

This topology consists of 3 cells, each cell contains two complementary switches $\left(T_{k}\right.$ and $T_{k}^{\prime}$, i.e, if $\left.T_{k}: \mathrm{ON} \mapsto \mathrm{T}_{k}{ }_{k}: \mathrm{OFF}\right)$ with $k \in\{1,2,3\}$, they can be controlled by a binary function $S_{k}(t) \in\{0,1\}$, it is defined by:

$$
S_{k}=\left\{\begin{array}{l}
1 \text { if } T_{k} \text { is } O N \\
0 \text { if } T_{k}^{\prime} \text { is } O N
\end{array}\right.
$$

These two states imply that the converter can have in general $2^{p}$ possible configurations, whether $\mathrm{p}$ is the number of cells. Between each two cells we insert flying capacitors as continuous sources. So, a multicellular inverter is composed by p-1 floating voltage sources either two in our case [15]. These $2^{p}$ configurations can be put together in a system of a differential equation representing the evolution of $V_{c_{i}}$ voltages with $\mathrm{i}=1, \ldots, \mathrm{p}-1$ and the load current $i_{o}$. The dynamical behavior of a 3-cell inverter is described as follows:

On the one hand, the output voltage is defined by:

$$
V_{o}=\left(S_{1}-S_{2}\right) V_{c 1}+\left(S_{2}-S_{3}\right) V_{c 2}+\left(S_{3}-\overline{S_{3}}\right) V_{i n}
$$

with $V_{\text {in }}$ is the input source that is equal to $\frac{E}{2}$.

On the other hand, the voltage across the load is:

$$
V_{o}=R i_{o}+L \frac{d i_{o}}{d t}
$$

So,

$$
\frac{d i_{o}}{d t}=\frac{1}{L} V_{o}-\frac{R}{L} i_{o}
$$

As a result:

$\frac{d i_{o}}{d t}=\frac{\left(S_{1}-S_{2}\right)}{L} V_{c 1}+\frac{\left(S_{2}-S_{3}\right)}{L} V_{c 2}+\frac{\left(S_{3}-\overline{S_{3}}\right)}{L} V_{i n}-\frac{R}{L} i_{o}$

For $i \in\{1,2\}$ we have the capacitor currents are equal to:

$$
i_{c i}=\left(S_{i+1}-S_{i}\right) i_{o}
$$

We still have:

$$
i_{c i}=C_{i} \frac{d V_{c i}}{d t}
$$

Consequently:

$$
\frac{d V_{c i}}{d t}=\frac{\left(S_{i+1}-S_{i}\right)}{C_{i}} i_{o}
$$

From equations (5) and (8) we determine our instantaneous model:

$$
\left\{\begin{array}{c}
\frac{d V_{c 1}}{d t}=\frac{\left(S_{2}-S_{1}\right)}{C_{1}} i_{o} \\
\frac{d V_{c 2}}{d t}=\frac{\left(S_{3}-S_{2}\right)}{C_{2}} i_{o} \\
\frac{d i_{o}}{d t}=\frac{\left(S_{1}-S_{2}\right)}{L} V_{c 1}+\frac{\left(S_{2}-S_{3}\right)}{L} V_{c 2}+\frac{\left(S_{3}-\overline{S_{3}}\right)}{L} V_{i n}-\frac{R}{L} i_{o}
\end{array}\right.
$$

The state space equations in (9) can be written in matrix form:

$$
\left[\begin{array}{c}
\dot{V_{c 1}} \\
\dot{V}_{c 2} \\
\dot{i_{o}}
\end{array}\right]=\left[\begin{array}{ccc}
0 & 0 & \frac{S_{2}-S_{1}}{C_{1}} \\
0 & 0 & \frac{S_{3}-S_{2}}{C_{2}} \\
\frac{S_{1}-S_{2}}{L} & \frac{S_{2}-S_{3}}{L} & -\frac{R}{L}
\end{array}\right] X+\left[\begin{array}{c}
0 \\
0 \\
\frac{S_{3}-\overline{S_{3}}}{L}
\end{array}\right] V_{i n}
$$

The model (10) represents a dynamical system, which can be expressed in a compact form as:

$$
\dot{X}=A_{q_{j}} X+B_{q_{j}} V_{i n}
$$

Where $A_{q_{j}} \in R^{3 x 3}$ and $B_{q_{j}} \in R^{3 x 1}, q_{j}$ represents the discrete variables, it is consisting of $2^{3}=8$ modes of operation, so $j \in\{0, \ldots, 7\}$. Each mode is given by a set of possible switching combinations called (SDD) (Specific discontinuous driving) $q_{k} \in\left\{S_{1}, S_{2}, S_{3}\right\} . \mathrm{X}$ is the state vector it represents the continuous part of the hybrid system. In order to ensure normal operations, a balanced distribution of the floating voltages should be necessary guarantee as agreed.

For 3-cell inverter we have:

$$
\left\{\begin{array}{l}
V c_{1}=\frac{E}{3} \\
V c_{2}=\frac{2 E}{3}
\end{array}\right.
$$


The table bellow represents a four-level inverter variables as function of SDDs [16]:

TABLE I

FOUR-LEVEL INVERTER VARIATION

\begin{tabular}{|c|c|c|c|c|}
\hline SDD & $S_{3}$ & $S_{2}$ & $S_{1}$ & $V_{o}$ \\
\hline$q_{0}$ & 0 & 0 & 0 & $-V_{i n}$ \\
\hline$q_{1}$ & 0 & 0 & 1 & $-\frac{V_{i n}}{3}$ \\
\hline$q_{2}$ & 0 & 1 & 0 & $-\frac{V_{i n}}{3}$ \\
\hline$q_{3}$ & 0 & 1 & 1 & $\frac{V_{i n}}{3}$ \\
\hline$q_{4}$ & 1 & 0 & 0 & $-\frac{V_{i n}}{3}$ \\
\hline$q_{5}$ & 1 & 0 & 1 & $\frac{V_{i n}}{3}$ \\
\hline$q_{6}$ & 1 & 1 & 0 & $\frac{V_{i n}}{3}$ \\
\hline$q_{7}$ & 1 & 1 & 1 & $V_{i n}$ \\
\hline
\end{tabular}

\section{Control StRategies}

\section{A. PWM control}

This control called pulse width modulation (PWM), it was chosen because of its simplicity of implementation where signals of each cell are obtained by the intersection between a triangular carrier and a modulating signal. This control requires the same number of the triangular carriers as cells. The carriers are shifted by $\delta=\frac{2 \pi}{p}$ either $\delta=\frac{2 \pi}{3}$ in our case. The following figure shows the offset between these carriers:

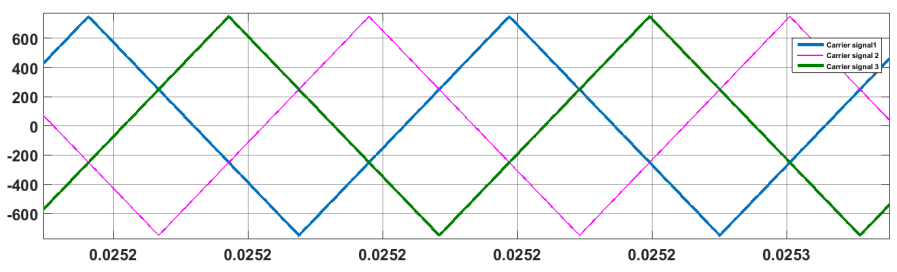

Fig. 2. Shifted carriers

This regular phase shift of the carriers relative to each other is important for two reasons:

- On the one hand, it allows the multilevel output voltage to reach its intermediate levels. Indeed, if all the carriers were inphase, all the cells would switch at the same time and be in the same state of conduction. Consequently, the output voltage would only reach its extreme values.

- On other hand, the regular phase shift multiply the apparent frequency of cutting of the output voltage, we not that this voltage gather with $\mathrm{p} * \mathrm{~F}$ with $\mathrm{F}$ is the switching frequency of each switch.

The objective of this strategy is to control the load current and the flying capacitor voltages. The principle is to assign (PI) controller to regulate the load current $i_{o}$, the internal voltages
$V_{c 1}$ and $V_{c 2}$ will be balanced naturally. The control diagram is presented in the following figure:

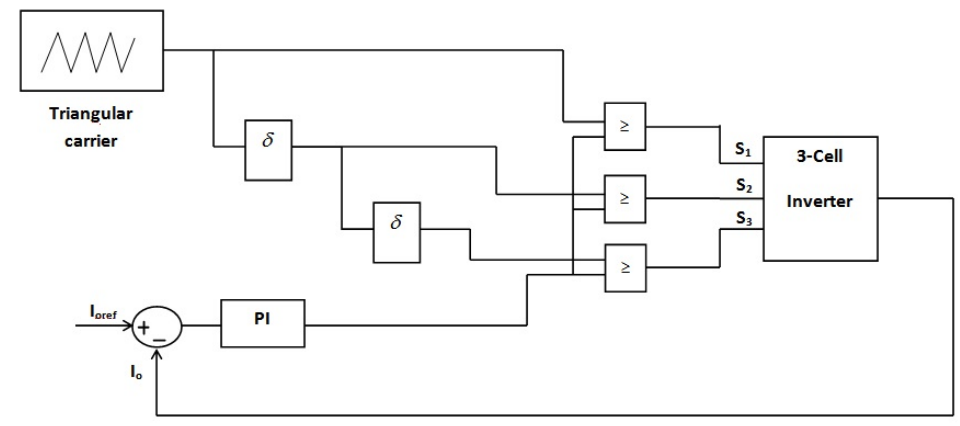

Fig. 3. PWM control diagram of a 3-cell inverter

\section{B. Petri Nets control strategy}

Petri Nets control is a bipartite graph of two types of nodes, it is composed by places and transitions connected between them by direct arcs. It is consider as a very effective and powerful tool in modelling hybrid systems, where the continuous part can be modeled by places and disrete state variables can be described by transitions. The principle of the control of switches is shown in the figure bellow:

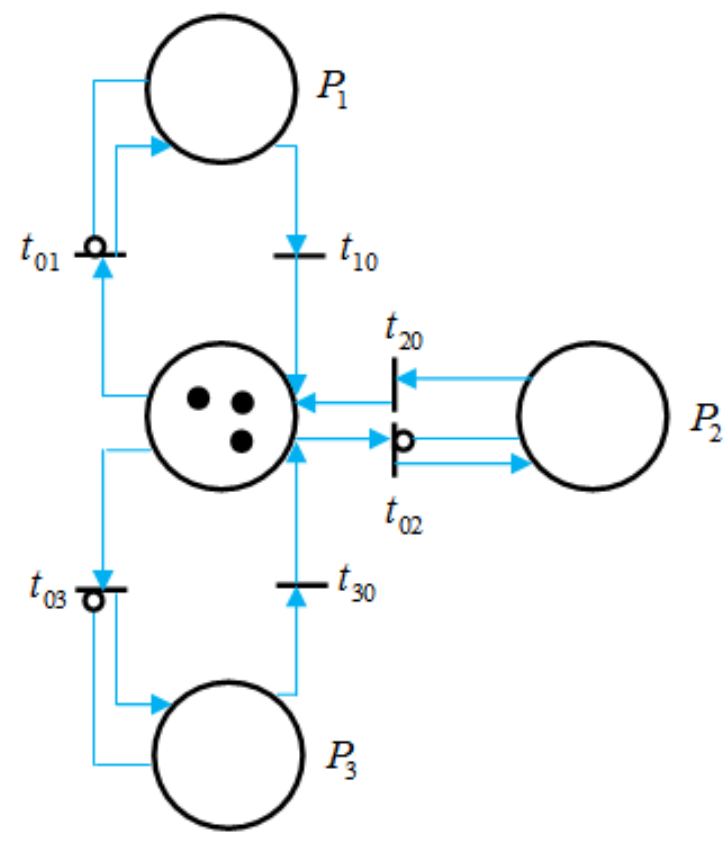

Fig. 4. Switch operating diagram

The control model diagram illustrated explains the regulation of the system, to ensure this control an hysteresis methodology is used. The diagram bellow shows its operation: 


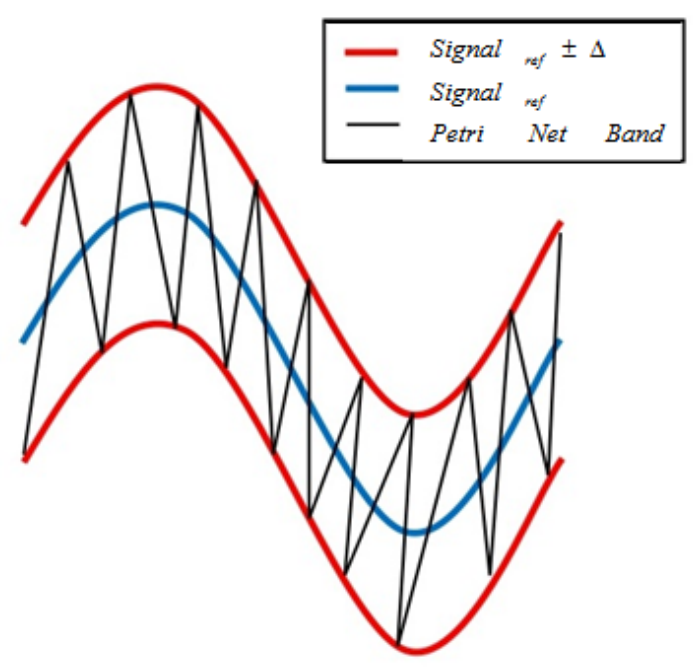

Fig. 5. Hysteresis methodology

An operating band is provided to remain the output carrent and the voltages of flying capacitors inside $i_{\text {oref }}-\Delta_{1} \leq i_{o} \leq$ $i_{\text {oref }}+\Delta_{1}$ and $V_{c_{i} \text { ref }}-\Delta_{2} \leq V_{c_{i}} \leq V_{c_{i} \text { ref }}+\Delta_{2}$ with $\Delta_{1}$ is the load current tolerance error and $\Delta_{2}$ is the capacitor voltage tolerance error.

The places model respectively the state of the switches cell $_{1}$, $\mathrm{cell}_{2}, \mathrm{cell}_{3}$ as shown in this table:

TABLE II

DESIGNATION OF PLACES

\begin{tabular}{|l|l|}
\hline Places & Designations \\
\hline P0 & Initial state \\
\hline P1 & Initial cell switching \\
\hline P2 & Second cell switching \\
\hline P3 & Third cell switching \\
\hline
\end{tabular}

The role of the inhibitor arcs is to prevent the presence of several tokens in the places.

Consider that $e_{i}$ is the current error. Closing the cells depends on the validation of the transitions $T_{i_{0}}$. The transition from one place to another depends on the state of the capacitor voltages and the current error as shown in the table bellow:
TABLE III

TRANSITION VALIDATION TABLE

\begin{tabular}{|c|l|}
\hline Transitions & \multicolumn{1}{|c|}{ Disignations } \\
\hline \multirow{5}{*}{$T_{10}$} & $\left(\mathrm{e}_{i} \geq \Delta_{1}\right)$ or \\
& $\left(-\Delta_{1} \leq e_{i} \leq \Delta_{1}\right)$ and $\left(V_{c_{1}}>\frac{E}{3}+\Delta_{2}\right)$ and $\left(i_{o}>0\right)$ or \\
& $\left(-\Delta_{1} \leq e_{i} \leq \Delta_{1}\right)$ and $\left(V_{c_{1}}<\frac{E}{3}-\Delta_{2}\right)$ and $\left(i_{o}<0\right)$ \\
\hline \multirow{5}{*}{$T_{20}$} & $\left(\mathrm{e}_{i} \geq \Delta_{1}\right)$ or \\
& {$\left[\left(-\Delta_{1} \leq e_{i} \leq \Delta_{1}\right)\right.$ and $\left(V_{c_{1}}<\frac{E}{3}-\Delta_{2}\right.$ or $V_{c_{2}}>\frac{2 E}{3}+$} \\
& $\left.\Delta_{2}\right)$ and $\left.\left(i_{o}>0\right)\right]$ or \\
& {$\left[\left(-\Delta_{1} \leq e_{i} \leq \Delta_{1}\right)\right.$ and $\left(V_{c_{1}}>\frac{E}{3}+\Delta_{2}\right.$ or $V_{c_{2}}<\frac{2 E}{3}-$} \\
& $\left.\Delta_{2}\right)$ and $\left.\left(i_{o}<0\right)\right]$ \\
\hline \multirow{5}{*}{$T_{30}$} & $\left(\mathrm{e}_{i} \geq \Delta_{1}\right)$ or \\
& $\left(-\Delta_{1} \leq e_{i} \leq \Delta_{1}\right)$ and $\left(V_{c_{2}}<\frac{2 E}{3}-\Delta_{2}\right)$ and $\left(i_{o}>0\right)$ or \\
& $\left(-\Delta_{1} \leq e_{i} \leq \Delta_{1}\right)$ and $\left(V_{c_{2}}>\frac{2 E}{3}+\Delta_{2}\right)$ and $\left(i_{o}<0\right)$ \\
\hline
\end{tabular}

\section{Simulation AND RESUlts}

The proposed model and controllers were simulated in MATLAB/Simulink with the following parameters:

$$
\left\{\begin{array}{c}
V i n=750 \mathrm{~V} \\
L=0.5 m \mathrm{H} \\
C_{1}=50 \mu \mathrm{F} \\
C_{2}=50 \mu \mathrm{F} \\
R=10 \Omega
\end{array}\right.
$$

We consider the reference current equal to:

$$
i_{\text {oref }}=20 \cos (2 \pi F t)
$$

For the PWM control, the frequency $\mathrm{F}$ is equal to $1600 \mathrm{~Hz}$. The admissible tolerance error for load current and capacitor voltage has been selected as follows

$$
\left\{\begin{array}{l}
\Delta_{1}=1 \\
\Delta_{1}=0.5
\end{array}\right.
$$

The evolution of the load current and the floating voltage for the PWM control is shown in these figures:

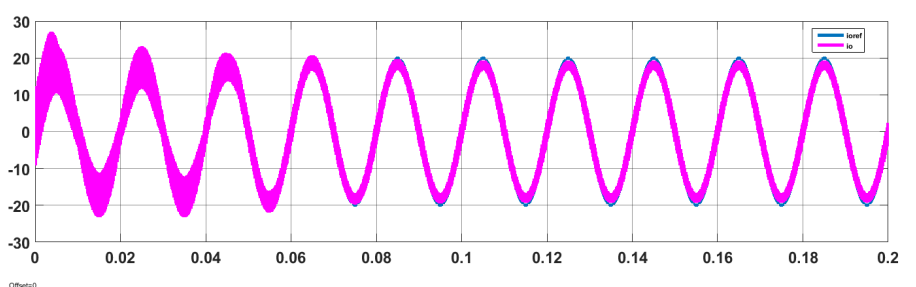

Fig. 6. Load current evolution for PWM control

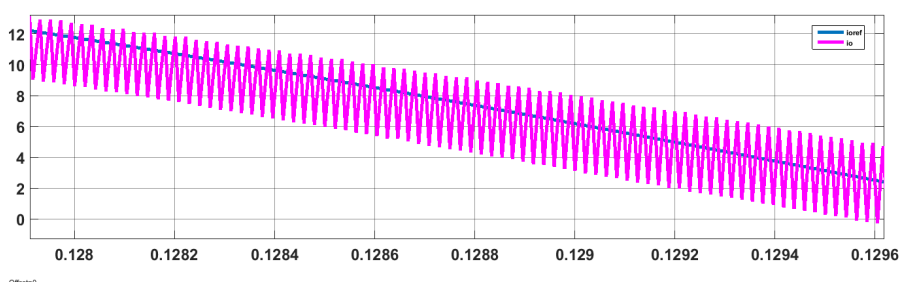

Fig. 7. Tracking of the load reference for PWM control 


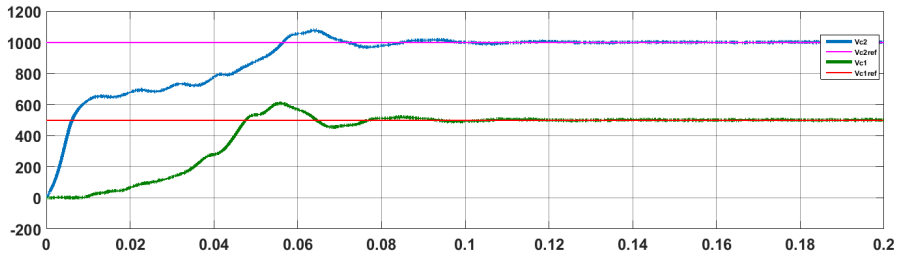

Fig. 8. Flying capacitor voltages for PWM control

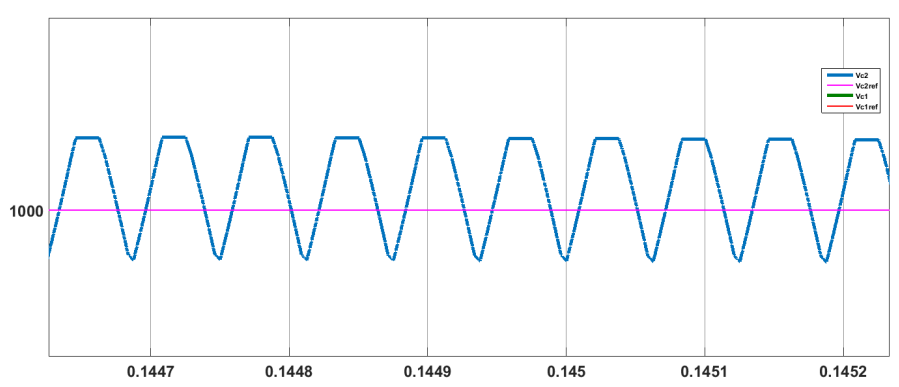

Fig. 9. Tracking of the flying capacitor voltage reference for PWM control

Then, the evolution of the load current and the floating voltages for the Petri Nets control is shown in these figures:

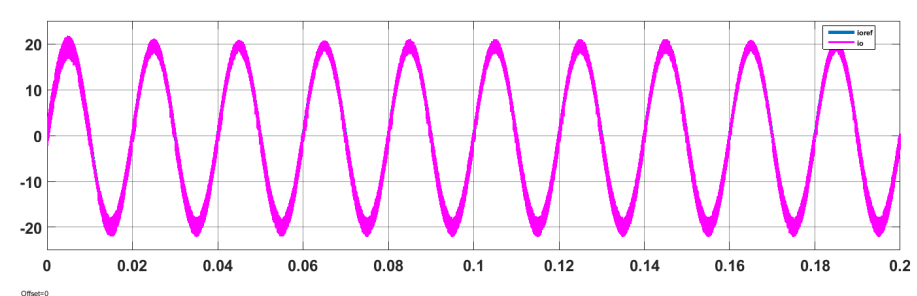

Fig. 10. Load current evolution for Petri Nets control

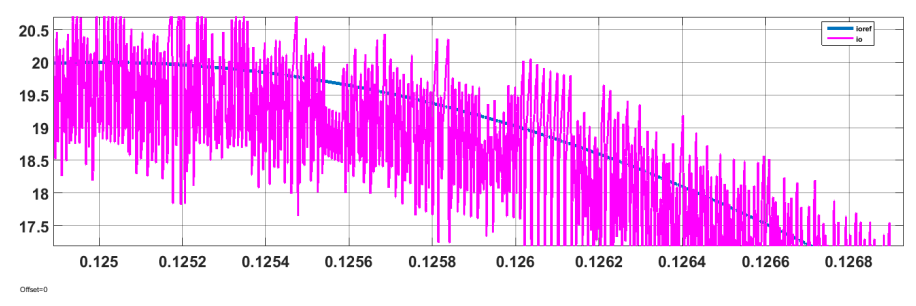

Fig. 11. Tracking of the load reference for Petri Nets control

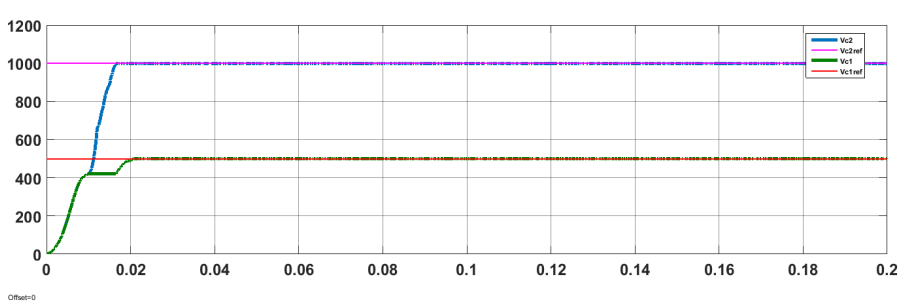

Fig. 12. Flying capacitor voltages for Petri Nets control

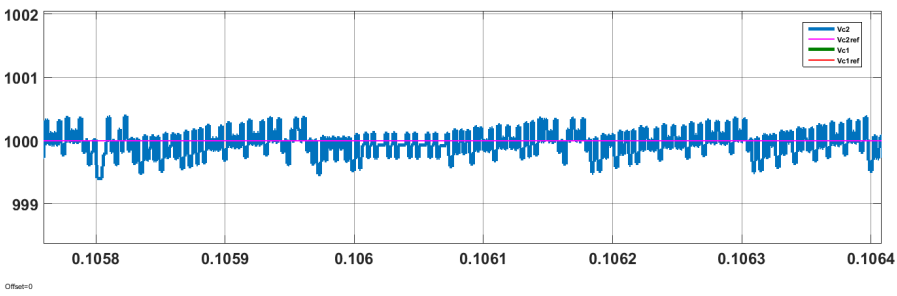

Fig. 13. Tracking of the flying capacitor voltage reference for Petri Nets control

Comparing these results, it noticed that the Petri Nets control is more robust. We can deduce that this control assure a good tracking of the load current, the measured load current reaches the proposed reference in a short time. We still notice that for the establishment of the flying capacitor voltages with Petri Nets control it takes $0.02 \mathrm{~s}$ against $0.1 \mathrm{~s}$ for PWM control. we can constate that the load current is perfectly maintained between the desired bands and the flying capacitor voltages are well balanced around the reference value. We concluded that this study provides a substantial improvement in the transition time, in the load current tracking and in the ripples of the floating voltages.

\section{CONClusion}

In this paper a modeling and control of a power converter topology DC/AC called multicellular inverter has been presented. The scheme of this control strategy is based on Petri Nets algorithm. This work shows the efficiency of controlling the output current and solving the problem related to the imbalance voltage branch. As long as multicellular systems combines discrete variables because of discontinuities in their mathematical models, Petri Nets are among the powerful tools for modeling. The proposed algorithm is based on the statements of voltage of flying capacitors and output current. An hysteresis operation is provided to remain these variables inside a specific band where we can adjust output current ripples and switching frequency. Finally, simulation results show the convergence of the voltage branch and the output current to a neighborhood of the value of the desired references. These simulation results were obtained to illustrate the performance and to improve the robustness of this control algorithm.

\section{REFERENCES}

[1] Leopoldo G Franquelo, Jose Rodriguez, Jose I Leon, Samir Kouro, Ramon Portillo, and Maria AM Prats. The age of multilevel converters arrives. IEEE industrial electronics magazine, 2(2):28-39, 2008.

[2] Mohamed Hamdi, Mahmoud Hamouda, Lassaad Sbita, and Kamal AlHaddad. Fcs-mpc for grid-tied three-phase three-level npc inverter with experimental validation. In 2017 International Conference on Green Energy Conversion Systems (GECS), pages 1-6. IEEE, 2017.

[3] Sergio Alberto Gonzalez, Santiago Andres Verne, and Maria Ines Valla Multilevel converters for industrial applications. CRC Press, 2016.

[4] Fang Lin Luo and Hong Ye. Advanced DC/AC inverters: applications in renewable energy. Crc Press, 2016.

[5] Peng Guo, Qianming Xu, Yufei Yue, Fujun Ma, Zhixing He, An Luo, and Josep M Guerrero. Analysis and control of modular multilevel converter with split energy storage for railway traction power conditioner. IEEE Transactions on Power Electronics, 35(2):1239-1255, 2019. 
[6] Francesco Tardelli, Alessandro Costabeber, David Trainer, and Jon Clare. Series chain-link modular multilevel ac/dc converter (scc) for hvdc applications. IEEE Transactions on Power Electronics, 2019.

[7] Emmanuel Yofo and Philippe Djondiné. Parallel active filtering based on a three-phase multicell converter. 2019.

[8] Mohamad Alaa Eddin Alali. Contribution à l'étude des compensateurs actifs des réseaux électriques basse tension. 2002.

[9] Philippe Djondiné, Jean-Pierre Barbot, and Malek Ghanes. On the petri nets control of the multicellular converter. 2017.

[10] Brendan Peter McGrath and Donald Grahame Holmes. Analytical determination of the capacitor voltage balancing dynamics for threephase flying capacitor converters. IEEE Transactions on Industry Applications, 45(4):1425-1433, 2009.

[11] A Ruderman, B Reznikov, and M Margaliot. Simple analysis of a flying capacitor converter voltage balance dynamics for dc modulation. In 2008 13th International Power Electronics and Motion Control Conference, pages 260-267. IEEE, 2008.

[12] Richardt H Wilkinson, Thierry A Meynard, and Hendrik du Toit Mouton. Natural balance of multicell converters: The general case. IEEE Transactions on Power Electronics, 21(6):1658-1666, 2006.

[13] Rabiaa Gamoudi, Dhia Elhak Chariag, and Lassaad Sbita. A review of spread-spectrum-based pwm techniques-a novel fast digital implementation. IEEE Transactions on Power Electronics, 33(12):10292-10307, 2018.

[14] Imen Mrad, Abdessamad Abdelhedi, Jean Pierre Barbet, and Lassaad Sbita. Robust hybrid observer for ibc based on z (tn)-observability. In 2017 International Conference on Green Energy Conversion Systems (GECS), pages 1-6. IEEE, 2017.

[15] Muhammad Humayun, Muhammad Mansoor Khan, Ali Muhammad, Jianming Xu, and Weidong Zhang. Evaluation of symmetric flying capacitor multilevel inverter for grid-connected application. International Journal of Electrical Power \& Energy Systems, 115:105430, 2020.

[16] Fernando Salinas, Malek Ghanes, Jean Pierre Barbot, Miguel F Escalante, and Bilal Amghar. Modeling and control design based on petri nets for serial multicellular choppers. IEEE Transactions on Control Systems Technology, 23(1):91-100, 2014 